\title{
The Effect of Infancy Radiation Exposure and Its Role as Ability Shifter in Estimating Return to Education
}

\author{
Teng-Jen Chang \\ The Ohio State University
}

The instrumental variables (IV) model is widely used in estimating returns to education. A key, untestable, assumption for the validity of IV is the exclusion restriction. In this paper, I revisit the common schooling instrument based on local college openings to evaluate its validity and estimate heterogeneity in treatment effects. To do this, I use infant radiation exposure in the U.S. in the early 1960s as a measurable shifter that affects the latent ability term, which is assumed to be independent of the IV. Under the IV assumptions, introducing a control function for latent ability should have no effect on the estimated return to schooling. I find that controlling for infancy radiation exposure does not significantly alter the IV estimates. Second, the latent ability shifter can be used to identify heterogeneity in IV treatment effects. I show that the estimated IV treatment effect of schooling on wages decreases sharply with infancy radiation exposure.

Keywords: instrumental variables, causal effects, environmental radiation, human capital, cognitive development, education, measurement error

\section{INTRODUCTION}

From the late 1950s to the early 1960s, main nuclear powers in the world experienced institutional changes in nuclear weapon testing. These changes led to substantial variation of environmental radiation across both space and time. Using the institutional change as a natural experiment, recent studies have demonstrated that prenatal exposure to environmental radiation during this period has significant impacts on long-run and short-run demographic and human capital outcomes, including educational attainment, school test scores, and sex ratio (Black et al. 2013, Chang 2017). In particular, Chang (2017) shows that for the U.S. 1960s birth cohort, individuals who experienced extreme radiation during their second prenatal quarters have approximately 0.9 less year of education compared with their counterparts. Environmental radiation in this period therefore provides measurable proxies that attribute to the heterogeneous latent abilities that can be used to evaluate the Instrumental Variable (IV) method regarding estimating the causal relationship of education and earnings.

The correlation between education and earnings has been long recognized by social scientists. Return to schooling is of interests to researchers mainly because of not only the emerging wage disparities among high- and low-educated workers, but also the rapid growth of secondary and higher education systems in developing countries. The cost of investment and its return in labor market performances are thus key issues to policymakers and people who actively make education decisions. However, the causal effect of education and wage cannot be trivially estimated because of the endogeneity problem. Unobservable factors such as cognitive abilities can determine educational attainment and labor market outcomes at the same time. A 
straight OLS estimate would therefore lead to a biased estimated return to education given researchers fail to control for the endogeneity. Rising literature in the past decades has suggested various econometric models that aim to estimating the unbiased effect of education on wage, which are surveyed and summarized in detail by Card (2001).

In this paper, I use the historical coincidence of nuclear testing policy changes and college openings to evaluate the Instrumental Variable (IV) estimation for return to education regarding its robustness to the exclusion restriction assumption. Return to education for population sample born in the United States between 1960 and 1966 is estimated using a 2SLS model. I consider the local number of two-year and fouryear colleges when an individual was age 17, i.e. 1977-1983, as instruments for educational attainment. ${ }^{1}$ The local number of colleges provides exogenous variation of geographic access to college education from the supply-side of the education market. Infancy radiation exposure experienced by the studied population sample at their age of 0 month to 12 months, constructed by historical radiation data, is introduced to the 2SLS estimation process as a shifter to unobserved latent abilities, which is embedded in the structural error term of the wage-education regression. When the exclusion restriction assumption is satisfied, controlling for the latent ability shifter does not affect the correlation of the IV and the structural error term, and therefore does not affect the resulting 2 SLS estimate. It is therefore possible to assess the validity of an IV regarding the exclusion restriction assumption by observing how the 2SLS estimate changes in response to including ability shifters in the structural regression.

The Instrumental Variable (IV) method is a well-developed and widely used approach to estimate the causal effect of education and solve endogeneity problems. Ideal candidates for instrumental variables should be exogenous and have significant effects on education. They should also be variables of sources that are correlated with educational attainment but uncorrelated with or independent to unobservable factors that together with educational attainment determine the wage rate. The requirement is referred as exclusion restriction in the literature. To meet these criteria, recent IV literature draws considerable attention to supply-side shocks to the education market, such as legal minimum dropout age, compulsory education policy changes, and physical proximity to schools.

One key challenge of the IV method is the fulfillment of exclusion restriction. Since exclusion restriction cannot be directly tested, it relies on the model assumption and the knowledge of the data. Investigation of the validity of the restriction and so as the validity of the instrumental variable has thus become a main task of the IV literature. Stephens and Yang (2014) re-estimate the return to education using instrumental variables proposed in the existing literature. They find that after controlling for region-specific time trends and region-specific birth year effects, many previous significant IV estimates become insignificant or of the opposite sign. These findings demonstrate the importance of validating the IV approach by addressing unobserved heterogeneity when estimating the education-wage causality.

I include infancy radiation in selected postnatal quarters of each individual as additional control covariates in the baseline 2SLS regression to test local college numbers' robustness to the exclusion restriction assumption, and so the validity of local college numbers as instruments for educational attainment. I find that although infancy radiation exposure is significantly associated with educational attainment, controlling for infancy radiation exposure does not significantly alter the 2SLS estimate for return to education. Regardless of the control for infancy radiation exposure, the 2SLS estimate for the effect of an additional year of education is approximately 23 percentage points in the wage rate. The magnitude is greater than the OLS estimate, which is 10.83 percentage points. The resistance of the 2SLS estimate to the inclusion of infancy radiation exposure suggests that the distribution of the education instrumented by local college numbers is uncorrelated with unobserved abilities, and thus provides no evidence of violation to the exclusion restriction assumption.

Since both the effect of local college numbers on education and the effect of education on wage can potentially vary with an individual's unobserved abilities, which can be captured by infancy radiation exposure, I examine the heterogeneity in treatment effects. Infancy radiation exposure is interacted with the key input variables in each stage of the 2SLS regression. The effect of two-year college numbers on education is scaled down by infancy radiation exposure in the third postnatal quarter, but the estimated return to education is not affected by the heterogeneous effect of two-year college numbers. The finding 
suggests that the validity of local college numbers as an IV for educational attainment is robust to alternative functional forms allowing heterogeneous treatment effects on education. I also find that the 2SLS estimate for the effect of education on wage decreases with infancy radiation exposure in the third postnatal quarter. For individuals who experienced an average level of radiation, the estimated return to education decreases from approximately 23 to approximately 15 percentage points. The distribution of the wage premium, described by the local average treatment effect, in response to the instrumented schooling significantly varies with infancy radiation exposure. It is therefore suggested that people's education decision in response to school numbers is not sensitive to different abilities. When there is an exogenous increase in the college education supply, people go to college nevertheless. However, return to education varies for people with different abilities. Even educational attainment is increased exogenously, people with lower abilities have smaller wage premium.

The paper proceeds as follows: In Section 2, I introduce the historical background of the IV (school openings) and exogenous shifter to the latent ability (environmental radiation) together with a literature review on the effect of early-life radiation exposure on health and human capital. Section 3 provides the summary of datasets used in this paper. Section 4 discusses the empirical strategy and results of controlling infancy radiation in a baseline IV model estimating returns to education. Section 5 extends the IV model with alternative functional forms to accommodate heterogeneity in treatment effects in the two stages of the 2SLS estimation. Section 6 concludes.

\section{BACKGROUND}

\section{School Openings}

The local number of colleges as the instrumental variable for schooling is originally proposed by Currie and Moretti (2003) to estimate the effect of maternal education on children's birth outcomes. Combining the school opening data from 1940 to 1990 with the Vital Statistics data from 1970 to 1999, they find that higher maternal education not only improves infants' health at birth but also increases the probability of the mother being married and the occurrence of other health behaviors.

The use of local school opening can be extended from the particular focus on the effect of women's education to estimating the causal effect of education on wage. For the second half of the 20th century, the United States experienced significant expansion of educational attainment. One driving factor of such expansion is the increasing supply of schools. According to the U.S. Department of Education, the medium years of education completed by an individual increased from 9.3 years in 1950 to 12.7 years in 1990; during the same period, the number of higher education institutes in the country increased by 91 percent. $^{2}$ The long-lasting and large-scale growth at the supply side of the education market is an ideal workhorse for researchers who are interested in investigating return to education for any given cohort born in the second half of the 20th century. The local number of schools can also be identified to different geographic levels to work together with other merging datasets that contain desired characteristics of the studied population sample. These features make school openings an ideal source of external supply-side variation that works together with environmental radiation to test various assumptions imposed on the baseline IV regression in this paper.

\section{Nuclear Weapon Testing}

People started practical use of nuclear weapon in 1945, since which nuclear tests were conducted until the 1990s. From 1945 to 1992, the United States conducted a total of 1,054 nuclear tests in the homeland or on overseas testing sites, according to official statistics. Most of these tests were conducted at the Nevada Testing Site (NTS); the remainder took place at sites in the Pacific Ocean, the Atlantic Ocean, and other locations in the United States. Radioactive fallouts generated by the nuclear explosions affected environmental radiation in a wide range of areas.

On October 31, 1958, the U.S. President Dwight Eisenhower announced that the United States was implementing a unilateral moratorium on nuclear weapon testing. The Soviet Union, the United Kingdom, and France later joined in, and the moratorium became multilateral de facto. No known nuclear tests were 
conducted by these countries for almost three years after that. On August 31, 1961, Nikita Khrushchev, the leader of the Soviet Union, announced that the country was abandoning the nuclear testing moratorium, which brought the multilateral moratorium to an end. On September 1, 1961, the Soviet Union began a nuclear weapon testing series that included the largest nuclear bomb (known as the "Tsar Bomba") in history. Two weeks later, the United States responded by resuming a series of nuclear tests at the NTS. In October 1963, the United States, the Soviet Union, and the United Kingdom ratified the Partial Nuclear Test Ban Treaty, which prohibited all forms of nuclear tests above ground, under water, and in space; after that these countries' nuclear tests were all conducted underground.

Figure 1 presents a summary box plot for beta radiation in air samples collected from selected U.S. cities between 1959 and 1966 (the radiation data is described in detail in the data section of this paper). Radiation fluctuations in the air closely reflect the institutional phase-in and phase-out of nuclear testing during this period. In 1959 and 1960, radiation detected across the United States was in very low doses and had little variation. These observations are consistent with the fact that no nuclear weapon tests were conducted during the moratorium period. A dramatic increase in both mean and variation of radiation occurred in 1961. The mean and variation of radiation is significantly greater in 1961, 1962, and 1963 than the rest of the period. It is noticeable that compared with radiation in 1962 and 1963, 1961 has a lower average, a greater variance, and more outlier observations. This is coherent to the fact that the Soviet Union and the United States broke the nuclear testing moratorium in late 1961, and there is, therefore, an even greater outspread of radiation detection in 1961. The plot of original raw radiation data is provided in the appendix.

\section{FIGURE 1 \\ GROSS BETA RADIATION IN AIR 1959-1966}

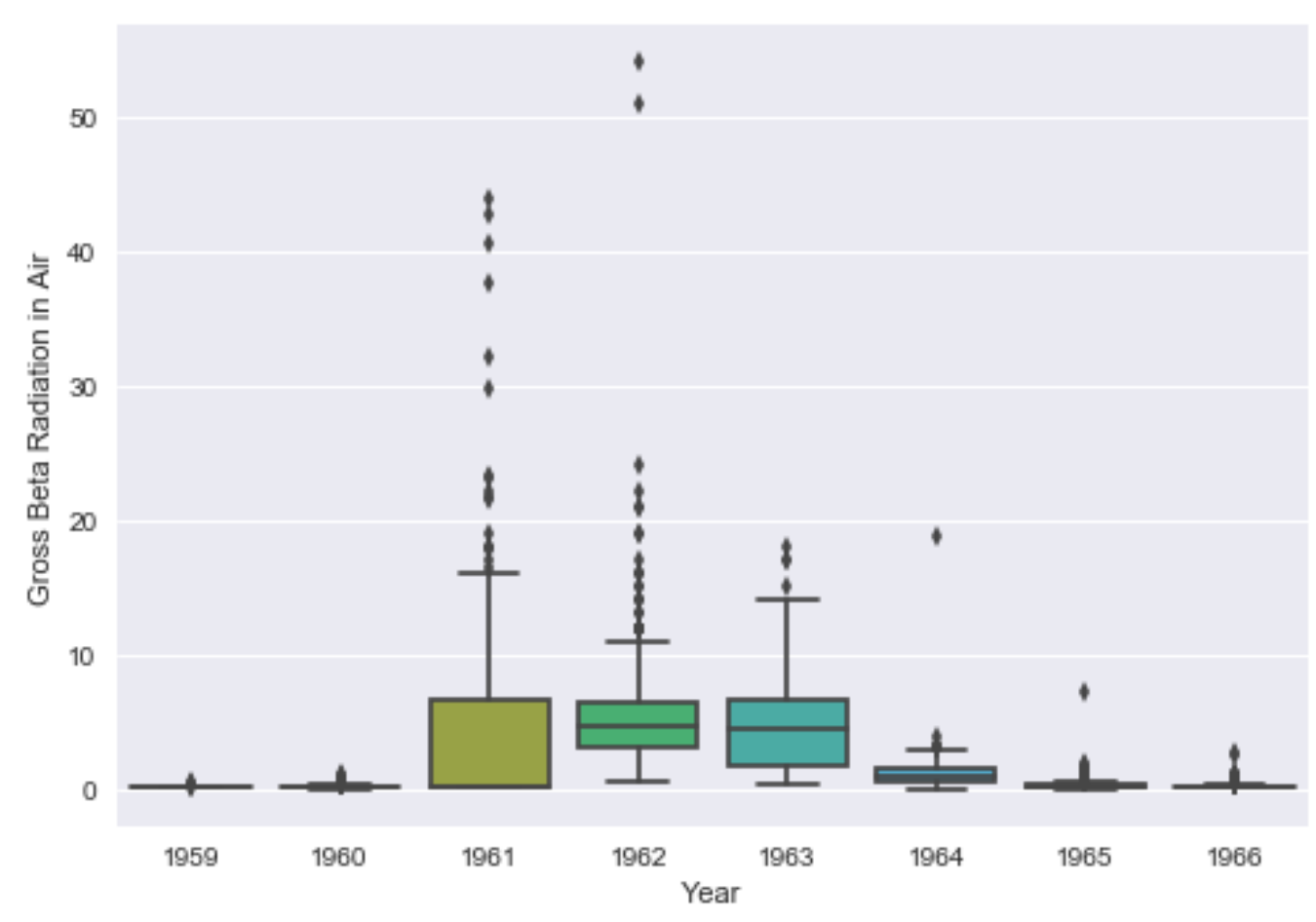

\section{Infancy Radiation Exposure}

In the medical and biological literature, it is suggested that radiation exposure during infancy and childhood has negative effects on health. The greatest practical concern comes from the justifiable use of radiological imaging or diagnostic procedure (e.g., X-rays and CT scans) in pediatrics. Potential health 
effects of radiation exposure include tissue destruction, cell loss, cell transformation, and damage in development (especially for early-life exposure). The epidemiological evidence has shown that even low dose exposure to ionizing radiation leads to higher risk of cancer. In particular, exposure during childhood leads to increased risk of leukemia, breast cancer, thyroid cancer, and mortality. The age dependence of the effect, however, is complex and is likely to follow a non-linear trend in age.

Recent development of economic literature on early-life exposure has utilized prominent historical nuclear events to examine the effect of prenatal radiation exposure on long-run and short-run human outcomes (Almond 2009, Black et al. 2013, and Chang 2017). These studies have found consistent results with medical and biological literature that during the middle part (especially the 8 th to the 25 th gestational week) of pregnancy, introduction of radiation has negative ejects on babies in utero. Besides, the negative effect is greater on males due to a gender-biased spontaneous abortion where male embryos are more likely to be killed in response to external shocks. These papers, though focusing on prenatal exposure rather than infancy or childhood exposure to radiation, have provided researchers with a well-established empirical framework that can be directly extended to examining the effect of infancy, or postnatal, exposure to radiation. Practically, an ideal natural experiment for testing prenatal radiation exposure can also serve as a natural experiment to examine the effect of postnatal radiation exposure. Individuals with available information of birth timing and birth locations can be linked to data with well-identified location and time where radiation is recorded to construct an individual's postnatal radiation exposure profile. One key difference between studying prenatal exposure and studying postnatal exposure is that the former assumes that the mother lived in the same place during the pregnancy and the occurrence of birth, while the later assumes that the baby lived in the same place during its infancy after birth.

\section{THE DATA}

\section{The Radiation Data}

I use the Radiological Health Data, published by the U.S. Department of Health, Education, and Welfare, to present the historical record of environmental radiation in the United States during the 1960s. The collection of environmental radiation data started in late 1959. Samples of air, water, and milk from various locations across the county were collected, and the radioactiveness of these samples was measured and recorded. I choose the data of radiation in the air sample to capture infants' spontaneous intake of environmental radiation.

The program of Public Health Service Radiation Surveillance Network, which was established in 1956, conducted the air sample collection. It operated with the Atomic Energy Commission to trace and monitor environmental radiation caused by nuclear weapon tests in the country. The air sample was collected weekly from local sampling stations in selected cities across the country and then sent to federal or local laboratories to analyze the radioactiveness. The dose of radiation in the air sample was reported monthly. At the beginning of the program, there were 44 sampling stations, with available radiation records in November 1959. The number of sampling stations varies but steadily grew overtime. In 1965, the number of sampling stations reached 74 within the United States. Over the whole decade of the 1960s, most states (and D.C.) had at least one and up to three sampling stations with available radiation records every month.

The summary statistics of radiation in the air sample between 1959 and 1966 are shown in Table 1. The overall radiation in air was of a low level in 1959 and 1960. In 1961, the average and the variation of air radiation went up significantly. The high level of radiation in air remained until 1963. Between 1961 and 1963, the average radiation ranges from 3.49 to 5.29, and the standard deviation of radiation ranges from 3.01 to 5.93. In 1964, the overall radiation in the air went down to a low level in both average and variation. This pattern is coherent with the historical fact that the U.S. was following the nuclear weapon testing moratorium announced in 1958, which was broken by the Soviet Union in September 1961. As the Partial Ban Treaty went into effect in late 1963, radiation in air reported afterward became low.

In this paper, I consider radiation measured in the quarterly manner to present radiation in each postnatal quarter of individuals in the population sample, so to reflect radiation exposure levels during different stages of their infancy. In Table 2, I report the summary statistics of the average and the maximum radiation in 
each quarter that is used to construct postnatal radiation exposure levels. ${ }^{3}$ The summary statistics of the average and the maximum radiation in the first quarters are thus not reported. It is shown that after the conversion, there is still variation in the data to investigate the outcomes of people who experienced a different level of radiation during their infancy.

\section{SUMMARY STATISTICS OF GROSS BETA RADIATION}

\begin{tabular}{cccccc}
\hline Year & Observations & Mean & Std. Dev. & Minimum & Maximum \\
\hline 1959 & 85 & 0.143 & 0.060 & 0.100 & 0.490 \\
1960 & 524 & 0.148 & 0.092 & 0.004 & 1.120 \\
1961 & 552 & 3.488 & 5.930 & 0.060 & 43.900 \\
1962 & 729 & 5.288 & 3.953 & 0.600 & 54.000 \\
1963 & 767 & 4.554 & 3.026 & 0.300 & 18.000 \\
1964 & 773 & 1.060 & 0.947 & 0.000 & 18.700 \\
1965 & 785 & 0.247 & 0.321 & 0.000 & 7.300 \\
1966 & 770 & 0.182 & 0.205 & 0.100 & 2.630 \\
\hline
\end{tabular}

Radiation is measured in picoCuries per cubic meters.

TABLE 2

SUMMARY STATISTICS OF GROSS BETA RADIATION IN POSTNATAL QUARTERS

\begin{tabular}{lcccc}
\hline & Mean & Std. Dev. & Minimum & Maximum \\
\hline First Postnatal Quarter (R1) & & & & \\
$N=331$ & 2.178 & 2.712 & 0.100 & 15.000 \\
$\begin{array}{l}\text { Quarterly Average } \\
\text { Quarterly Maximum }\end{array}$ & 2.621 & 3.171 & 0.100 & 17.000 \\
$\begin{array}{l}\text { Second postnatal quarter } \\
\text { R2) }\end{array}$ & & & \\
$N=334$ & & & & \\
Quarterly Average & 1.886 & 3.399 & 0.100 & 40.600 \\
$\begin{array}{l}\text { Quarterly Maximum } \\
\text { Third postnatal quarters }\end{array}$ & 3.394 & 6.634 & 0.100 & 51.000 \\
(R3) & & & & \\
$N=376$ & & & & \\
Quarterly Average & 2.302 & 3.482 & 0.065 & 14.667 \\
Quarterly Maximum & 3.130 & 4.825 & 0.100 & 32.000 \\
\hline
\end{tabular}

Radiation is measured in picoCuries per cubic meters

\section{The School Opening Data}

I choose college opening as the instrumental variable to capture the exogenous determinant to the educational attainment of people born in the 1960s from the supply side of higher education. This IV is first proposed by Currie and Moretti (2003). They use the variation of local college numbers and openings at the college-entry age of women (17 years old) to study the effect of maternal education on birth outcomes of babies born between 1970 and 1999. The college opening data is obtained from the Integrated Postsecondary Education Data System (IPEDS) issued by the National Center for Education Statistic, together with the Peterson's Guide to Four-year colleges (1999) and Barron's Profiles of American Colleges (1996). ${ }^{4}$

Table 3 reports the summary statistics of college numbers in each Public Use Metropolitan Area (PUMA, the smallest geographic identification unit for every interviewee in the ACS data, where population samples born in the 1960s studied in this paper are extracted.) between 1977 and 1983, when 
people born between 1960 and 1966 turned age 17. In the table, the number of four-year colleges, the number of two-year colleges, the number of four-year colleges per thousand people, and the number of twoyear colleges per thousand people are listed. During 1977 and 1983, each PUMA has an average of 5.05 four-year colleges (standard deviation 7.62) and an average of 3.68 two-year colleges (standard deviation 5.63). The average number of four-year colleges is 0.0075 (standard deviation 0.0064 ), and the average number of two-year colleges is 0.0059 (standard deviation 0.0052 ).

TABLE 3

SUMMARY STATISTICS OF COLLEGE NUMBERS IN PUMA-LEVEL, 1977-1983

\begin{tabular}{lccccc}
\hline & Observations & Mean & Std. Dev. & Minimum & Maximum \\
\hline 4-Year College (FYC) & 30954 & 5.052 & 7.624 & 0.000 & 48.000 \\
2-Year College (TYC) & 30954 & 3.678 & 5.635 & 0.000 & 38.000 \\
FYC per 1000 People & 30687 & 0.008 & 0.006 & 0.000 & 0.050 \\
TYC per 1000 People & 30687 & 0.006 & 0.005 & 0.000 & 0.059 \\
\hline
\end{tabular}

\section{The 1960s Cohort Sample Data}

I choose the 2005-2015 ACS (American Community Survey) data to present the national population sample of the United States. The sample is constrained to people born in the first quarter between 1960 and 1966. The selection of the birth quarter is to accommodate the measurement error problem in the birth year, which is described in detail in the next subsection. I further limited the sample to individuals born in the 50 states and D.C.

In the ACS data, individual level variables of birth state, birth quarter, and birth year are available. These variables are used to link the population sample to the environmental radiation data to construct measurements of radiation exposure during the cohort members' infancy. When utilizing the school opening as an instrumental variable for education, the information of the place of residence when age 17 is required. I used the PUMA of residence at the survey to proxy the PUMA of residence when the individual was age 17 , so to link the population sample data to the school opening data to construct the number of colleges when the individual was 17 years old. Educational attainment variables are constructed by the years of education at the interview. In order to estimate the effect of instrumented education on wage income, I adjusted the annual salary income by the 1988-based CPI. I calculate the individual hourly wage rate by dividing the annual salary income by the self-reported hours of work in the year prior to the survey year. ${ }^{5}$ The summary statistics of years of education, hourly wage rates for the analyzed population sample are reported by sex and race in Table 4.

TABLE 4

SUMMARY STATISTICS OF THE 1960-1966 COHORT POPULATION SAMPLE

\begin{tabular}{lcccccc}
\hline & \multicolumn{3}{c}{ Males } & & Females \\
\cline { 2 - 7 } & Observations & Mean & Std. Dev. & Observations & Mean & Std. Dev. \\
\hline Education (Years) & 340399 & 13.34 & 2.69 & 358865 & 13.58 & 2.56 \\
Age (Years) & 340399 & 47.17 & 3.72 & 358865 & 47.15 & 3.74 \\
White & 340399 & 0.85 & 0.36 & 358865 & 0.84 & 0.37 \\
Black & 340399 & 0.10 & 0.31 & 358865 & 0.12 & 0.32 \\
Other Races & 340399 & 0.05 & 0.21 & 358865 & 0.05 & 0.21 \\
Hourly Wage & 293101 & 13.49 & 39.82 & 281125 & 10.10 & 31.41 \\
Rate & & & & & \\
\hline
\end{tabular}




\section{Selection of the Cohort Sample}

In this paper, I choose the ACS sample individuals born in the first quarters (January-March) between 1960 and 1966. The selection of the birth year is due to the time window where environmental radiation was substantially affected by nuclear testing in the early part of the 1960s; the selection of the birth quarter is based on the nature of error-measured birth year in the public-use ACS data. In the ACS data, the year of birth is a second-hand variable calculated from subtracting the survey year by the self-reported real age at the interview. Therefore, people who were interviewed before their birthdays would report the real age they had reached in the year prior to the survey year. In this case, the calculated birth year would be one year ahead of the actually birth year. Because the birth year is critical in determining the level of infancy radiation exposure, the misallocated birth year leads to misallocated infancy radiation exposure, and as a result yields biased estimates for the effect of infancy radiation exposure. Intuitively, the earlier the birthday is, the lass probable the birth year is miscalculated.

In my previous paper (Chang 2017), I address the issue of measurement error in the ACS data, and provided with a formalized regression model to correct for the measurement error bias. Consider a data generating process:

$Y_{t}=\beta X_{t}+\epsilon$

There is a probability $p$ that $Y_{t}$ is generated by $X_{t-1}$ instead of $X_{t}$. However. Researchers cannot distinguish whether each observation of $Y_{t}$ is generated by $X_{t}$ or $X_{t-1}$. The naive regression of $Y_{t}$ on $X_{t}$ gives an estimate $\beta_{\text {error }}$, while the true effect of $X$ on $Y$ is $\beta_{\text {true. }}$. I showed that:

$\beta_{\text {error }}=(1-p) \beta_{\text {true }}+p \operatorname{Cov}\left(X_{t}, X_{t-1}\right) \beta_{\text {true }}$

The estimated effect is a weighted combination of the probability of regressor misallocation $p$, the covariance of $X_{t}$ and $X_{t-1}$, and the true effect $\beta_{\text {true }}$. In this model setting, since both $\operatorname{Cov}\left(X_{t}, X_{t-1}\right)$ and $p$ takes a value strictly within $[0,1], \beta_{\text {error }}$ cannot exceed $\beta_{\text {true }}$, and is always downward biased.

The above equation provides a formalized relationship to assess the measurement error bias once $p$ and $\operatorname{Cov}\left(X_{t}, X_{t-1}\right)$ are known. In the context of this infancy radiation exposure research, since $X_{t}$ and $X_{t-1}$ are quarterly environmental radiation observed one-year apart, the serial correlation is very week. Therefore, the measurement error bias equation can be further degenerated to:

$\beta_{\text {error }}=(1-p) \beta_{\text {true }}$

To recover the possible true effect of infancy radiation exposure, I make the further assumption that both birthdays and interview days are uniformly distributed throughout the year, and thus have $p$ equals 0.125 if people are born in the first three months of the year.

\section{ESTIMATING THE RETURN TO EDUCATION}

\section{The Model}

To understand the validity of school openings as instrumental variables for education, I start with the standard structure of regressions with two stages. Following the literature, the baseline IV model takes the form as follows:

Baseline IV Model

$$
\begin{aligned}
& Y_{s t, i}=\alpha_{1}+\beta_{s 1} S_{s t, i}+\delta_{1} X_{s t, i}+A_{i}+\eta_{1 s t, i} \\
& S_{s t, i}=a_{1}+b_{F 1} F_{s t, i}+b_{T 1} T_{s t, i}+c_{1} X_{s t, i}+v_{1 s t, i}
\end{aligned}
$$


In the above equations, $Y_{s t, i}$ is the log hourly wage of individual $i$ born in state $s$ and year $t, S$ is years of education of the individual. $X$ includes age, age square, race dummies, whether living in metropolitan areas, state-level unemployment rate in the survey year, a linear time trend (2005-2015), and birth state fixed effect. The unobservable ability $A_{i}$ and the residual $\eta_{1 s t, i}$ together compose the structural error term $\epsilon_{1 s t, i}=A_{i}+\eta_{1 s t, i} . F$ and $T$ compose the set of instrumental variables for schooling, presenting the number of four-year colleges per thousand people and the number of two-year colleges per thousand people in the year when an individual was 17 years old and in the residential Public Use Metropolitan Areas (PUMAs) of the individual at the interview. ${ }^{6}$

To serve as valid instruments for educational attainment, the local college number should satisfy the conditions suggested by the IV literature that (1) $F$ and $T$ have significant predictive power to education $S$, and that (2) $F$ and $T$ are uncorrelated with the structural error term $\epsilon_{1 s t, i}($ e.g. $\operatorname{Corr}(F, \epsilon)=\operatorname{Corr}(T, \epsilon)=$ $0)$. In the literature, the satisfaction of the second condition depends on the knowledge of the data and reasonable assumptions. Technically, the exclusion restriction cannot be directly tested since $\epsilon_{1 s t, i}$ is unobservable. However, given the additional information of infancy radiation exposure, it is possible to test the robustness of the assumption of exclusion restriction.

Given that $\epsilon_{1 s t, i}$ can be expressed as $A_{i}+\eta_{1 s t, i}$, where $A_{i}$ denotes an individual's ability to earn wage income aside from the benefit from education. Consider infancy radiation exposure $R$ which is strong enough to shift the ability so that $\operatorname{Corr}\left(A_{i}, R\right) \neq 0$ and thus $\operatorname{Corr}(\epsilon, R) \neq 0$. If local college numbers satisfy the exclusive restriction, additional information regarding $A$ does not affect the correlation of local college numbers and the structural error term, since they are uncorrelated with $A$.

In this case, educational attainment instrumented by local college numbers should be as well uncorrelated with $\epsilon$ in the second-stage wage equation, and generate consistent estimates for the return to education. Including information of $R$ in the IV model would not alter the 2SLS estimate, since it does not alter the fact that the instrumented schooling is uncorrelated with $\epsilon$. In contrast, if local college numbers violate the exclusion restriction and are correlated with $A$ and thus $S$, it should be observed that the inclusion of $R$ in the IV model alters the 2SLS estimates for the return to education. This is because the distribution of the instrumented schooling is correlated with unobserved abilities, which can be partially proxied by $R$. Therefore, the validity of local college numbers as instrumental variables to educational attainment can be tested by including infancy radiation exposure in the IV estimation.

In baseline IV model the controlled covariates included in $X$ do not contain the individual's heterogeneous latent characteristics. I consider alternative definitions of $R$ to present the state-quarter level environmental radiation in the individual's first, second, and third post-natal quarters. ${ }^{7}$ With postnatal radiation included additional controls variables, the two-stage regressions become IV Model (1):

\section{Model (1)}

$$
\begin{aligned}
& Y_{s t, i}=\alpha_{2}+\beta_{S 2} S_{s t, i}+\beta_{R 2} R_{s t, i}+\delta_{2} X_{s t, i}+\epsilon_{2 s t, i} \\
& S_{s t, i}=a_{1}+b_{F 2} F_{s t, i}+b_{T 2} T_{s t, i}+b_{R 2} R_{s t, i}+c_{12} X_{s t, i}+v_{2 s t, i}
\end{aligned}
$$

In the above model specification, I consider alternative definitions of infancy radiation exposure $R$ : radiation in the first postnatal quarter, radiation in the second post natal quarter, and radiation in the third postnatal quarter. In the result tables, I refer them as $R_{1}, R_{2}$, and $R_{3}$, and the estimates are reported respectively. I chose to include each of these $R$ 's and analyzed the models separately so to leave flexibility of testing the effect of infancy radiation exposure on estimating the 2SLS model in more complicated functional forms. Considering radiation in different postnatal quarters separately makes regression models estimate and comparable with each other. Details of these models are provided in the next section.

The baseline IV model and IV Model (1) are estimated with the 2SLS method, and the results are reported in the following subsection. Throughout the estimation, variance-covariance is clustered by stateyear groups. The sample includes people born in the first quarter of the year 1960 to $1966{ }^{8}$ 


\section{Results}

Tables 5 and 6 report the first-stage estimates for the effect of local numbers of four- and two-year colleges on years of education from the baseline IV model and IV Model (1). In the baseline IV model, standard geographic and demographic covariates are controlled in the first stage, and the estimate is reported in Column (1). In IV Model (1), infancy radiation exposure added as control covariates to present unobserved latent abilities), and the estimates are reported from Columns (2) to (4) depending on the definition of infancy radiation exposure considered. The effect of local numbers of four-year colleges per thousand people is significantly positive on years of education, between 7.35 to 7.56 years. For the local number of two-year colleges per thousand people, the effect is significantly negative years of education, between minus 16.56 and minus 17.14 years. Throughout the columns, the magnitudes and directions of the effect of local college numbers on educational attainment are persistent regardless of the inclusion of infancy radiation exposure as additional control covariates.

TABLE 5

\section{FIRST STAGE: EFFECTS OF COLLEGE NUMBERS AND RADIATION (QUARTERLY AVERAGE) ON EDUCATION}

\begin{tabular}{lcccc}
\hline & $(1)$ & $(2)$ & $(3)$ & $(4)$ \\
\hline$F$ & $7.5646^{* * *}$ & $7.4278^{* * *}$ & $7.3733^{* * *}$ & $7.3502^{* * *}$ \\
$T$ & $(1.4505)$ & $(1.4931)$ & $(1.4822)$ & $(1.4764)$ \\
$R_{1}$ & $-16.5648^{* * *}$ & $-17.1098^{* * *}$ & $-17.1331^{* * *}$ & $-17.1099^{* * *}$ \\
$R_{2}$ & $(1.3374)$ & $(1.3563)$ & $(1.3471)$ & $(1.3458)$ \\
$R_{3}$ & & 0.0011 & & \\
& & $(0.0021)$ & & \\
Age & & & 0.0021 & \\
Age Square & & & $(0.0021)$ & $-0.0062^{* * *}$ \\
& & & -0.0194 \\
Black & -0.0355 & -0.0381 & -0.0417 & $(0.0360)$ \\
& $(0.0340)$ & $(0.0361)$ & $(0.0354)$ & 0.0000 \\
Other Races & 0.0001 & 0.0002 & 0.0002 & $(0.0004)$ \\
& $(0.0004)$ & $(0.0004)$ & $(0.0004)$ & $-0.9663^{* * *}$ \\
Metropolitan & $-0.9616^{* * *}$ & $-0.9660^{* * *}$ & $-0.9648^{* * *}$ & $(0.0213)$ \\
& $(0.0208)$ & $(0.0216)$ & $(0.0213)$ & $-0.7247^{* * *}$ \\
Unemployed & $-0.7340^{* * *}$ & $-0.7219^{* * *}$ & $-0.7231^{* * *}$ & $(0.0353)$ \\
& $(0.0358)$ & $(0.0354)$ & $(0.0353)$ & $0.8355^{* * *}$ \\
$N$ & $0.8300^{* * *}$ & $0.8399^{* * *}$ & $0.8383^{* * *}$ & $(0.0217)$ \\
$R^{2}$ & $(0.0218)$ & $(0.0218)$ & $(0.0217)$ & 0.0022 \\
F-Statistics & 0.0027 & 0.0026 & 0.0025 & $(0.0030)$ \\
Stand & $(0.0029)$ & $(0.0030)$ & $(0.0030)$ & 261204 \\
& & & 0.0601 \\
& 267184 & 255697 & 259371 & 126.27 \\
\hline
\end{tabular}

Standard errors in parentheses

$* \mathrm{p}<0.05, * * \mathrm{p}<0.01, * * * \mathrm{p}<0.001$

IV first stage estimates for the effect of local college numbers on years of education with alternative inclusion of infancy radiation exposure in the regression. $F$ is the number of four-year colleges per thousand people in the PUMA of residence. $T$ is the number of two-year colleges per thousand people in the PUMA of residence. In Column (1), 
the regression of education on local college numbers does not include infancy radiation exposure. In Columns (2) to (4), average Infancy radiation exposure in the three postnatal quarters $R_{1}, R_{2}$, and $R_{3}$ used as shifters of unobserved latent abilities, and are included as additional control variables separately. Age, age square, race, whether living in metropolitan areas, the state-level unemployment, a linear trend of the survey year, the birth state fixed effect, and the birth year fixed effect are included as controlled covariates. Standard errors are clustered by the birth state and the birth year.

TABLE 6

\section{FIRST STAGE: EFFECTS OF COLLEGE NUMBERS AND RADIATION (QUARTERLY MAXIMUM) ON EDUCATION}

\begin{tabular}{lcccc}
\hline & $(1)$ & $(2)$ & $(3)$ & $(4)$ \\
\hline$F$ & $7.5646^{* * *}$ & $7.4248^{* * *}$ & $7.3698^{* * *}$ & $7.3536^{* * *}$ \\
$T$ & $(1.4505)$ & $(1.4932)$ & $(1.4823)$ & $(1.4763)$ \\
$R_{1}$ & $16.5648^{* * *}$ & $-17.1150^{* * *}$ & $-17.1369^{* * *}$ & $-17.1054^{* * *}$ \\
$R_{2}$ & $(1.3374)$ & $(1.3565)$ & $(1.3473)$ & $(1.3459)$ \\
$R_{3}$ & & -0.0014 & & \\
Age & & $(0.0018)$ & & \\
Age Square & & & 0.0013 & \\
Black & & & & \\
& & & & $-0.0047^{* * *}$ \\
Other Races & -0.0355 & -0.0302 & -0.0417 & $(0.0012)$ \\
& $(0.0340)$ & $(0.0363)$ & $(0.0355)$ & -0.0182 \\
Metropolitan & 0.0001 & 0.0001 & 0.0002 & $0.0361)$ \\
& $(0.0004)$ & $(0.0004)$ & $(0.0004)$ & $(0.0004)$ \\
Unemployed & $-0.9616^{* * *}$ & $-0.9660^{* * *}$ & $-0.9649^{* * *}$ & $-0.9661^{* * *}$ \\
& $(0.0208)$ & $(0.0216)$ & $(0.0213)$ & $(0.0213)$ \\
$N$ & $-0.7340^{* * *}$ & $-0.7220^{* * *}$ & $-0.7230^{* * *}$ & $-0.7244^{* * *}$ \\
$R^{2}$ & $(0.0358)$ & $(0.0354)$ & $(0.0353)$ & $(0.0353)$ \\
F-Statistics & $0.8300^{* * *}$ & $0.8399^{* * *}$ & $0.8384^{* * *}$ & $0.8354^{* * *}$ \\
\hline Stand & $(0.0218)$ & $(0.0218)$ & $(0.0217)$ & $(0.0217)$ \\
& 0.0027 & 0.0024 & 0.0025 & 0.0021 \\
& $(0.0029)$ & $(0.0030)$ & $(0.0030)$ & $(0.0030)$ \\
& 267184 & 255697 & 259371 & 261204 \\
& 0.0606 & 0.0598 & 0.0601 & 0.0601 \\
& 126.49 & 123.42 & 125.62 & 126.18 \\
\hline
\end{tabular}

Standard errors in parentheses

$* \mathrm{p}<0.05, * * \mathrm{p}<0.01, * * * \mathrm{p}<0.001$

IV first stage estimates for the effect of local college numbers on years of education with alternative inclusion of infancy radiation exposure in the regression. $F$ is the number of four-year colleges per thousand people in the PUMA of residence. $T$ is the number of two-year colleges per thousand people in the PUMA of residence. In Column (1), the regression of education on local college numbers does not include infancy radiation exposure. In Columns (2) to (4), maximum Infancy radiation exposure in the three postnatal quarters $R_{1}, R_{2}$, and $R_{3}$ used as shifters of unobserved latent abilities, and are included as additional control variables separately. Age, age square, race, whether living in metropolitan areas, the state-level unemployment, a linear trend of the survey year, the birth state fixed effect, and the birth year fixed effect are included as controlled covariates. Standard errors are clustered by the birth state and the birth year. 
Only radiation in the third postnatal quarter has a significant effect on years of education. A unit increase in the average radiation in the third postnatal quarter comes with a decrease in educational attainment by 0.0062 years; a unit increase in the maximum radiation in the third postnatal quarter comes with a decrease in educational attainment by 0.0047 years. The estimated effects of radiation in the third postnatal quarter are robust to an alternative definition of quarterly-level radiation. For the cohort sample studied in this paper, those born in the first quarters from 1960 to 1966, the mean and the standard deviation of the quarterly average in their third postnatal quarter are 2.3 and 3.48 picoCurie per cubic meters, and the mean and the standard deviation of the quarterly maximum in their third postnatal quarter are 3.13 and 4.83 picoCurie per cubic meters. Therefore, an individual who experienced an average level of radiation in his/her third postnatal quarter has less educational attainment by $0.0062 \times 2.3=0.0143$ years or $0.0047 \times 3.13=0.0147$ years. For those who experienced radiation of one standard deviation beyond the average, their educational attainment is decreased by $0.0062 \times 5.78=0.0358$ years or $0.0047 \times 7.96=$ 0.0374 years. Radiation in the first and the second postnatal quarters does not have significant effects on educational attainment in the regression of education on local college numbers.

Table 7 provides a closer observation of whether infancy radiation exposure has additional explanatory power to educational attainment in the regression of education on local college numbers. I calculate the residuals of the regression of education on local college numbers (the first stage regression of the baseline IV model) and regress the residuals on infancy radiation exposure. It is shown that only radiation in the third postnatal quarter has significant negative effects on the education residuals. When including radiation in all three postnatal quarters to the regression, radiation in the second postnatal quarter has a significant positive effect on the education residuals, but the effect does not persist when including radiation in the second postnatal quarter alone in the regression. The result suggests that infancy radiation exposure has very little additional explanatory power to the distribution of educational attainment predicted by local college numbers. Only radiation in the third postnatal quarter has a marginal attribute to the educational attainment net of college numbers. ${ }^{9}$

TABLE 7

EFFECTS OF RADIATION ON EDUCATION NET OF COLLEGE NUMBERS

\begin{tabular}{lcccc}
\hline \multicolumn{5}{c}{ PANEL A: POSTNATAL RADIATION MEASURED IN QUARTERLY AVERAGE } \\
\hline$R_{1}$ & $(1)$ & $(2)$ & $(3)$ & $(4)$ \\
\hline$R_{2}$ & 0.0014 & & & -0.0016 \\
& $(0.0018)$ & 0.0017 & & $(0.0019)$ \\
$R_{3}$ & & $(0.0014)$ & & $0.0151^{* * *}$ \\
& & & $-0.0042^{* * *}$ & $(0.0021)$ \\
& & & $(0.0012)$ & $-0.0096^{* * *}$ \\
$N$ & & & $(0.0015)$ \\
$R^{2}$ & 322007 & 326751 & 328980 & 322007 \\
\hline
\end{tabular}




\begin{tabular}{lcccc}
\hline \multicolumn{5}{c}{ PANEL B: POSTNATAL RADIATION MEASURED IN QUARTERLY MAXIMUM } \\
& $(1)$ & $(2)$ & $(3)$ & $(4)$ \\
\hline$R_{1}$ & -0.0012 & & & 0.0002 \\
$R_{2}$ & $(0.0015)$ & 0.0011 & & $(0.0016)$ \\
& & $(0.0007)$ & & $0.0040^{* * *}$ \\
$R_{3}$ & & & $-0.0034^{* * *}$ & $(0.0008)$ \\
& & & $(0.0009)$ & $-0.0054^{* * *}$ \\
$N$ & & & $(0.0010)$ \\
$R^{2}$ & 322007 & 326751 & 328980 & 322007 \\
\hline
\end{tabular}

Standard errors in parentheses

$* \mathrm{p}<0.05, * * \mathrm{p}<0.01, * * * \mathrm{p}<0.001$

This table reports the OLS estimates for the residual of the first-stage education equation for the Baseline IV Model on infancy radiation exposure.

In Table 8, I calculate and compare the effect of education on log wage income estimated with an OLS regression and with the baseline IV model. The OLS estimate for the return to education is significantly 10.83 percentage points, and the 2SLS estimates are 23.17 percentage points. Standard F-statistics is 126.49, large enough to reject the hypothesis that local college numbers are weak instruments for educational attainment.

TABLE 8

OLS AND IV SECOND STAGE: EFFECTS OF EDUCATION ON LOG WAGE

\begin{tabular}{lcc}
\hline & $(1)$ & $(2)$ \\
$S$ & OLS & 2SLS \\
\hline$N$ & $0.1083^{* * *}$ & $0.2317^{* * *}$ \\
$R^{2}$ & $(0.0008)$ & $(0.0185)$ \\
Cragg-Donald F-Statistics & & \\
Kleibergen-Paap F-Statistics & 69868 & 267184 \\
\hline
\end{tabular}

Standard errors in parentheses

$* p<0.05, * * p<0.01, * * * p<0.001$

This table reports the OLS estimates and the 2SLS estimates for the effects of education on log wage income. Education is instrumented by local college numbers in the first stage of the 2SLS estimation. Age, age square, race, whether living in metropolitan areas, the state-level unemployment, a linear trend of the survey year, the birth state fixed effect, and the birth year fixed effect are included as controlled covariates. Standard errors are clustered by the birth state and the birth year.

In Table 9, the 2SLS estimates for the return to education with infancy radiation exposure controlled in the first stage, as presented by IV Model (1), are reported. Compared with the 2SLS estimates obtained from the baseline IV model, the 2SLS estimates obtained from IV Model (1) shift up a bit to a value between 23.23 and 23.62 percentage points. These results suggest that the subpopulation who are mostly affected by the local college numbers regarding their education outcomes is not significantly shifted in the population distribution by infancy radiation exposure. It is worth noticing that the inclusion of radiation in the third postnatal quarter $\left(R_{3}\right)$ in the first stage shifts the 2SLS estimates for the return to education the most, from 23.17 percentage points to 23.6 percentage points. It is possible that the most instrumented 
group, after controlling for $R_{3}$, becomes those who could have benefited slightly more from education. However, the overall distribution of exogenously determined educational attainment is not affected by the inclusion of $R$ 's, suggesting that local college numbers are a valid instrument, robust to the assumption that $\operatorname{Corr}(F, \epsilon)=0$ and $\operatorname{Corr}(T, \epsilon)=0$.

TABLE 9

\section{SECOND STAGE: EFFECTS OF EDUCATION ON LOG WAGE CONTROLLING FOR RADIATION}

\begin{tabular}{lcccccc}
\hline & \multicolumn{3}{c}{$\begin{array}{c}\text { Radiation Measured } \\
\text { in Quarterly Average }\end{array}$} & \multicolumn{3}{c}{$\begin{array}{c}\text { Radiation Measured } \\
\text { in Quarterly Maximum }\end{array}$} \\
\cline { 2 - 7 } & $(1)$ & $(2)$ & $(3)$ & $(4)$ & $(5)$ & $(6)$ \\
& $R_{1}$ & $R_{2}$ & $R_{3}$ & $R_{1}$ & $R_{2}$ & $R_{3}$ \\
\hline$S$ & $0.2323^{* * *}$ & $0.2346^{* * *}$ & $0.2362^{* * *}$ & $0.2324^{* * *}$ & $0.2346^{* * *}$ & $0.2361^{* * *}$ \\
& $(0.0189)$ & $(0.0187)$ & $(0.0187)$ & $(0.0189)$ & $(0.0187)$ & $(0.0187)$ \\
$N$ & & & & & & \\
Cragg-Donald F- & 186.757 & 189.886 & 190.878 & 186.808 & 189.907 & 190.850 \\
Statistics & & & & & & \\
Kleibergen-Paap F- & 123.362 & 125.616 & 126.270 & 123.421 & 125.625 & 126.179 \\
Statistics & & & & & & \\
\hline
\end{tabular}

Standard errors in parentheses

$* p<0.05, * * p<0.01, * * * p<0.001$

This table reports the 2SLS estimates for the effects of education on log wage income. The first stage of the 2SLS estimation, infancy radiation exposure is included as an additional control variable. Alternative definition of (quarterly average and quarterly maximum) radiation in each of the first three postnatal quarters are considered respectively. For Columns (1) and (4), radiation in the first postnatal quarter is considered; for Columns (2) and (5), radiation in the second postnatal quarter is considered; for Columns (3) and (6), radiation in the third postnatal quarter is considered. Age, age square, race, whether living in metropolitan areas, the state-level unemployment, a linear trend of the survey year, the birth state fixed effect, and the birth year fixed effect are included as controlled covariates. Standard errors are clustered by the birth state and the birth year.

\section{HETEROGENEITY IN TREATMENT EFFECTS}

\section{The Model}

I further examine heterogeneity in treatment effects in the IV estimation for the return to education. A classical setting of IV estimation assumes both uniform effects the instrument variable on schooling in the first stage and uniform effects of the instrumented schooling on the wage in the second stage. With infancy radiation exposure, I consider alternative functional forms in the two stages of the IV model to capture potential heterogeneity in treatment effects that may change with individual's unobserved characteristics.

I begin with examining the heterogeneous treatment effect of local college numbers on educational attainment. Given the local number of colleges to an individual, the educational outcomes can be sensitive to his/her abilities, affected by radiation exposure during infancy, to gain education through school openings. The effect of college numbers on education is therefore assumed to vary with the individual's infancy radiation exposure. The assumption can be formalized by interacting infancy radiation exposure $R$ with the local college numbers $F$ and $T$ in IV Model (2):

IV Model (2)

$Y_{s t, i}=\alpha_{3}+\beta_{S 3} S_{s t, i}+\beta_{R 3} R_{s t, i}+\delta_{3} X_{s t, i}+\epsilon_{3 s t, i}$ 


$$
S_{s t, i}=a_{3}+b_{F 3} F_{s t, i}+b_{T 3} T_{s t, i}+b_{R 3} R_{s t, i}+b_{F R 3} F_{s t, i} \times R_{s t, i}+b_{T R 3} T_{s t, i} \times R_{s t, i}+c_{3} X_{s t, i}+v_{3 s t, i}
$$

Using this modified first-stage regression, it is testable whether individuals with different infancy radiation exposure have different education outcomes in response to supply-side shocks of the college education. Meanwhile, since $F$ and $T$ present the access to different level of post-secondary education, the most-instrumented population should be different in $R$, which proxies their unobserved abilities. If infancy radiation exposure is more relevant to the variation of abilities at the lower end of the ability distribution, it should be observed that the interaction of radiation and two-year college numbers takes more effect than does the interaction of radiation and four-year college numbers. It is noticeable that in estimating the effect of instrumented schooling on wage, the instrumented $S$ accommodates the effect of $F$ and $T$ to vary with $R$. Here the schooling is predicted by the instrument $F$ and $T$ together with radiation $R$ and the interactions $F R$ and $T R$. Because $R$ is correlated with unobserved ability, and so are $F R$ and $T R$. They should not be excluded from the second stage. Therefore, in the practical estimation process, the set of instrumental variables, therefore, remains the original set of $F$ and $T$.

The purpose of the above modifications to the baseline IV model (IV Model (1) and IV Model (2)) are meant to investigate the effect of infancy radiation exposure on the distribution of the educational attainment instrumented by local college numbers. The IV literature suggests the 2SLS estimates from these estimates should be interpreted as the local average treatment effect (LATE). In the context of this paper, the estimates from IV Model (1) and IV Model (2) are the return to education for the subpopulation whose marginal decision on education was affected by combinations of local college numbers and infancy radiation exposure. Infancy radiation exposure, as an external source of heterogeneity in abilities, can also be utilized to investigate the distribution of local average treatment effects for the subpopulation target by the college number instrument.

An extension to examine the distribution of the local average treatment effect is to allow infancy radiation exposure to take effect in the second-stage wage equation of the IV regression model. The formalized model can be written as IV Model (3):

\section{Model (3)}

$$
\begin{aligned}
& Y_{s t, i}=\alpha_{4}+\beta_{S 4} S_{s t, i}+\beta_{S R 4} S_{s t, i} \times R_{s t, i}+\delta_{4} X_{s t, i}+\epsilon_{3 s t, i} \\
& S_{s t, i}=a_{4 S}+b_{F 4 S} F_{s t, i}+b_{T 4 S} T_{s t, i}+c_{4 S} X_{s t, i}+v_{4 S s t, i} \\
& S_{s t, i} \times R_{s t, i}=a_{4 S R}+b_{F 4 S R} F_{s t, i}+b_{T 4 S R} T_{s t, i}+c_{4 S R} X_{s t, i}+v_{4 S R s t, i}
\end{aligned}
$$

In this model, I assume that the effect of education $S$ on wage $Y$ varies with infancy radiation exposure $\mathrm{R}$. In this case, an additional exogenous variable $S \times R$ is included in the second stage regression to address the assumption. Because the inclusion of infancy radiation in the first-stage education equation has little effects on the 2SLS estimates, I choose to allow infancy radiation exposure $R$ to appear solely in the secondstage education-radiation interaction $S \times R$. Since we have two instrumental variables $F$ and $T$, and two instrumented variables $\mathrm{S}$ and $S \times R$, the system is just identified.

The structure with two endogenous variables and two instrumental variables justifies the model specification of IV Model (1) and IV Model (2) where radiation in each postnatal quarter is included in separate analyses. This model specification strategy guarantees the conference and comparability throughout IV Model (1) to IV Model (3). If radiation in multiple postnatal quarters is included in IV Model (3), the model would not be estimable.

\section{Results}

Table 10 reports the first-stage results of Model (2), where the effect of college numbers is allowed to vary with infancy radiation exposure. The effect of local four-year college numbers is not strongly affected 
by the inclusions of radiation $R$ and the interactions $F \times R$ and $T \times R$, ranging from 7.15 to 7.81. However, the effect of local two-year college numbers is affected by the inclusion of radiation exposure in the third postnatal quarter, dropping from about minus 17 years to about minus 19 years. A unit increase in the average radiation in the third postnatal quarter comes to an increase in the marginal effect of local two-year college number of education by 0.686 year; a unit increase in the maximum radiation in the third postnatal quarter comes with an increase in the marginal effect of local two-year college number of education by 0.538 year. The effect of radiation and its interaction with college numbers only significant for radiation in the third postnatal quarter and its interaction with local two-year college numbers. These results suggest that the education decision for people going to four-year colleges is not significantly affected by the ability shifter. The decision for people going to two-year colleges is more affected by the ability shifter. For people with high radiation exposure in their third postnatal quarter, they obtain the education by either keeping attending four-year colleges or increasing consumption of two-year colleges.

TABLE 10

IV FIRST STAGE: EFFECTS OF COLLEGE NUMBERS ON EDUCATION VARYING WITH RADIATION

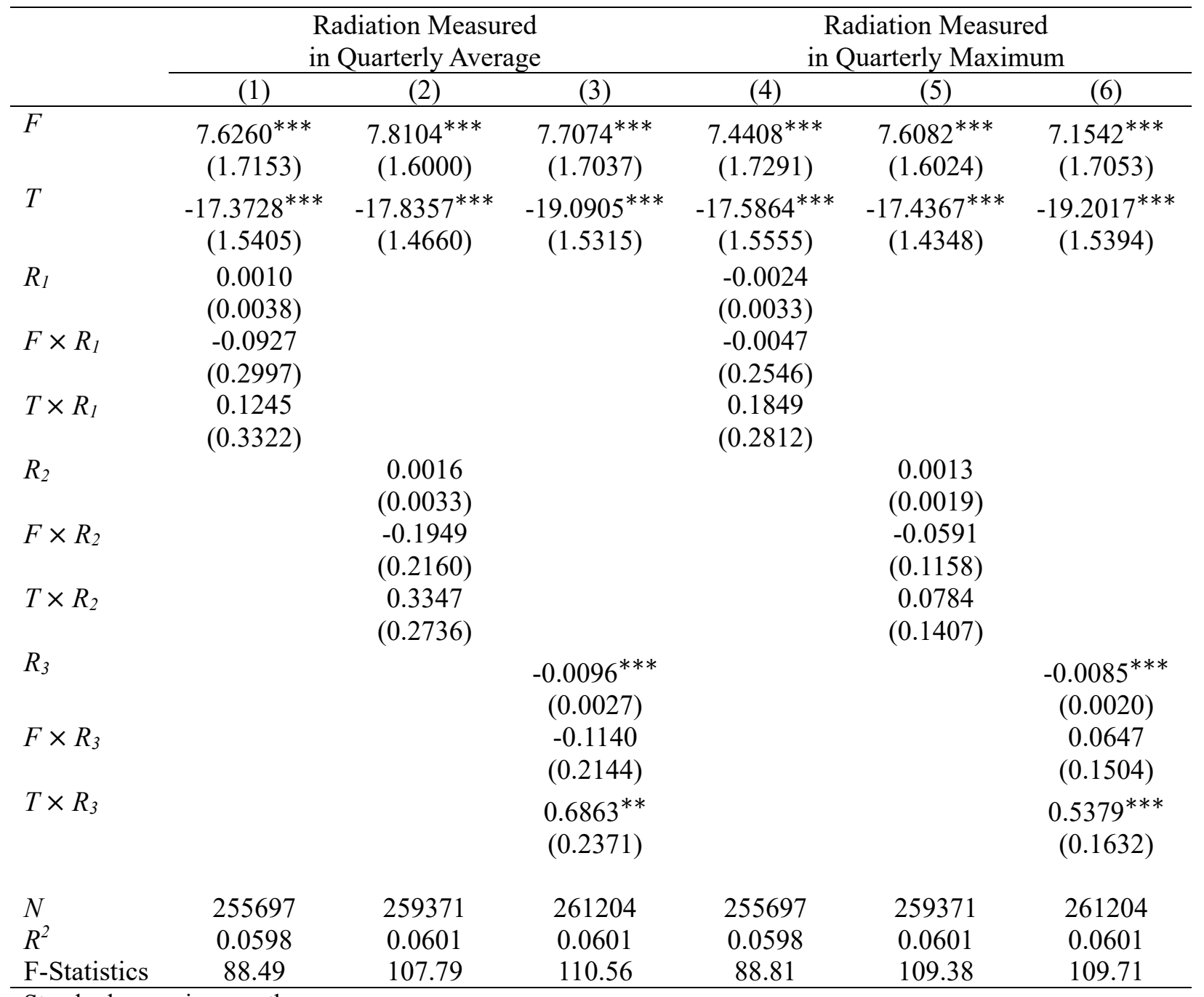

Standard errors in parentheses

$* p<0.05, * * p<0.01, * * * p<0.001$ 
This table reports the IV first-stage estimates for the effect of local college numbers on years of education. Effects of local colleges are allowed to vary with alternative definition of (quarterly average and quarterly maximum) radiation in each of the first three postnatal quarters. $F$ is the number of four-year colleges per thousand people in the PUMA of residence. T is the number of two-year colleges per thousand people in the PUMA of residence. For Columns (1) and (4), radiation in the first postnatal quarter is considered; for Columns (2) and (5), radiation in the second postnatal quarter is considered; for Columns (3) and (6), radiation in the third postnatal quarter is considered. Age, age square, race, whether living in metropolitan areas, the state-level unemployment, a linear trend of the survey year, the birth state fixed effect, and the birth year fixed effect are included as controlled covariates. Standard errors are clustered by the birth state and the birth year.

Table 11 shows the second-stage 2SLS estimates for Model (2), where the effect of IVs on education varies with infancy radiation exposure in the first stage. The overall size of the local average treatment effect is shifted down a bit to a size between 21.75 and 23.99 percentage points. The 2SLS estimates for the return to education are only slighted affected by the college-radiation interaction in the first stage. The marginal population with a slightly smaller return to education is mostly affected by the new set of instruments that takes effects with unobserved abilities.

TABLE 11

IV SECOND STATE: EFFECTS OF EDUCATION ON LOG WAGE VARYING WITH RADIATION

\begin{tabular}{|c|c|c|c|c|c|c|}
\hline & \multicolumn{3}{|c|}{$\begin{array}{l}\text { Radiation Measured } \\
\text { in Quarterly Average }\end{array}$} & \multicolumn{3}{|c|}{$\begin{array}{l}\text { Radiation Measured } \\
\text { in Quarterly Maximum }\end{array}$} \\
\hline & (1) & (2) & (3) & (4) & (5) & (6) \\
\hline & $R_{1}$ & $R_{2}$ & $R_{3}$ & $R_{1}$ & $R_{2}$ & $R_{3}$ \\
\hline$S$ & $\begin{array}{l}0.2175^{* * *} \\
(0.0226)\end{array}$ & $\begin{array}{c}0.2189^{* * *} \\
(0.0199)\end{array}$ & $\begin{array}{c}0.2277^{* * *} \\
(0.0207)\end{array}$ & $\begin{array}{c}0.2202^{* * *} \\
(0.0228)\end{array}$ & $\begin{array}{c}0.2286^{* * *} \\
(0.0202)\end{array}$ & $\begin{array}{c}0.2399^{* * *} \\
(0.0210)\end{array}$ \\
\hline$N$ & 255697 & 259371 & 261204 & 255697 & 259371 & 261204 \\
\hline $\begin{array}{l}\text { Cragg-Donald F- } \\
\text { Statistics }\end{array}$ & 125.408 & 161.931 & 155.606 & 124.082 & 159.077 & 158.277 \\
\hline $\begin{array}{l}\text { Kleibergen-Paap F- } \\
\text { Statistics }\end{array}$ & 88.492 & 107.790 & 110.555 & 88.810 & 109.382 & 109.706 \\
\hline \multicolumn{7}{|c|}{$\begin{array}{l}\text { This table reports the } 2 \text { SLS estimates for the effect of education on log wage income. The first-stage effects of local } \\
\text { colleges vary with alternative definition of (quarterly average and quarterly maximum) radiation in each of the first } \\
\text { three postnatal quarters. For Columns (1) and (4), radiation in the first postnatal quarter is considered; for Columns } \\
\text { (2) and (5), radiation in the second postnatal quarter is considered; for Columns (3) and (6), radiation in the third } \\
\text { postnatal quarter is considered. Age, age square, race, whether living in metropolitan areas, the state-level } \\
\text { unemployment, a linear trend of the survey year, the birth state fixed effect, and the birth year fixed effect are } \\
\text { included as controlled covariates. Standard errors are clustered by the birth state and the birth year }\end{array}$} \\
\hline
\end{tabular}

Table 12 presents the results of the first-stage regression of IV Model (3), where the education-radiation interaction is regressed on local college numbers. In IV Model (3), the effect of the two IV's (local numbers of four- and two-year colleges) on the additional endogenous variable of $S \times R$ (so that the effect of education can vary with infancy radiation exposure). The other first-stage regression of IV Model (3) is identical to the first-stage regression of the baseline IV model, of which the results are reported in Column (1) of Table 5. The local number of four- and two-year colleges do not have significant effects on $S \times R_{1}$ and $S \times R_{2}$. In fact, standard F-statistics (smaller than 10) for testing weak instruments suggests that local college numbers are not ideal IVs for the interaction of education and radiation in the first or the second postnatal quarter. In contrast, for the interaction of education and the third postnatal quarter radiation 
$S \times R_{3}$, the power of IV in the first stage is satisfying and make valid IVs for this additional endogenous variable to be instrumented. It is thus suggested that researchers should focus on interpreting the secondstage 2SLS estimates with $R_{3}$ considered.

\section{TABLE 12 \\ IV FIRST STAGE: EFFECTS OF COLLEGE NUMBERS ON EDUCATION-RADIATION INTERACTIONS}

\begin{tabular}{lcccccc}
\hline & \multicolumn{3}{c}{$\begin{array}{c}\text { Radiation Measured } \\
\text { in Quarterly Average }\end{array}$} & \multicolumn{3}{c}{$\begin{array}{c}\text { Radiation Measured } \\
\text { in Quarterly Maximum }\end{array}$} \\
\cline { 2 - 7 } & $(1)$ & $(2)$ & $(3)$ & $(4)$ & $(5)$ & $(6)$ \\
& $S \times R_{1}$ & $S \times R_{2}$ & $S \times R_{3}$ & $S \times R_{1}$ & $S \times R_{2}$ & $S \times R_{3}$ \\
\hline$F$ & 1.1506 & 9.9037 & $81.5682^{* * *}$ & 1.2560 & 56.7936 & $121.5286^{* * *}$ \\
& $(11.3635)$ & $(15.5208)$ & $(15.5208)$ & $(13.2155)$ & $(32.2609)$ & $(22.0538)$ \\
& $-67.8348^{* * *}$ & -24.4964 & $58.5673^{* *}$ & $-67.5057^{* * *}$ & -7.5743 & $90.0175^{* * *}$ \\
& $(15.4950)$ & $(17.9761)$ & $(18.9516)$ & $(18.4300)$ & $(38.5225)$ & $(27.1447)$ \\
$N$ & & & & & & \\
$R^{2}$ & 255697 & 259371 & 255697 & 259371 & 261204 & 255697 \\
F-Statistics & 0.0434 & 0.1426 & 0.2152 & 0.0417 & 0.1512 & 0.1754 \\
\hline Standaris & 9.84 & 1.21 & 18.59 & 6.86 & 1.58 & 20.92 \\
\hline
\end{tabular}

Standard errors in parentheses

$* p<0.05, * * p<0.01, * * * p<0.001$

This table reports the IV first stage estimates for the effect of local college numbers on the interaction of education years $\$ S \$$ and infancy radiation exposure $R$. The interaction of $S$ and $R$ serve as an additional endogenous variable in the IV regression to allow the effect of education on wage to vary with infancy radiation exposure in the second stage. $F$ is the number of four-year colleges per thousand people in the PUMA of residence. $T$ is the number of twoyear colleges per thousand people in the PUMA of residence. Infancy radiation exposure in the three postnatal quarters $R_{1}, R_{2}$, and $R_{3}$ are used as shifters of unobserved latent abilities. Alternative definitions of $R \mathrm{~s}$ as the average and the maximum radiation in each of the individual's postnatal quarters are considered separately. Age, age square, race, whether living in metropolitan areas, the state-level unemployment, a linear trend of the survey year, the birth state fixed effect, and the birth year fixed effect are included as controlled covariates. Standard errors are clustered by the birth state and the birth year.

Table 13 reports the second-stage 2SLS estimates for Model (3), where the effect of instrumented education varies with infancy radiation exposure in the second stage. Based in the findings reported in Table 12, it is suggested a focus on Column (3) and Column (6), where the inclusion of $S \times R_{3}$ remains college numbers valid IV's. The results reported in Column (1), (2), (4) and (5) are estimates from weakly identified instruments (Cragg-Donald F-statistics and Kleibergen-Paap F-Statistics are smaller than 2), and thus provide no information. The effect of the instrumented educational attainment decreases with infancy radiation exposure in the third postnatal quarter. For an individual with zero radiation exposure in his/her third postnatal quarter, the effect of an additional year of education on log wage income is about 24 (23.99 or 23.66 depending on the definition of the quarterly radiation level) percentage points. For an individual with a mean level of the average radiation exposure in his/her third postnatal quarter, the return to education goes from 23.99 percentage points to $23.99-4.03 \times 2.3=14.72$ percentage points. For an individual with a mean level of the maximum radiation exposure in his/her third postnatal quarter, the return to education goes from 23.66 percentage points to $23.66-2.68 \times 3.1=15.35$ percentage points. The positive return to education is completely gone for people having an average radiation of 5.95 unit (the maximum is 14.67) in his/her third postnatal quarter. The 2SLS estimates for the effect of education $S$ on $\log$ wage income and the 2SLS estimates for the effect of the education-radiation interaction $S \times R$ together suggest a distribution of return to education for people whose college are instrumented by local college numbers and infancy radiation exposure takes different levels. 


\section{TABLE 13 \\ IV SECOND STAGE: EFFECTS OF EDUCATION AND EDUCATION-RADIATION INTERACTIONS ON LOG WAGE}

\begin{tabular}{|c|c|c|c|c|c|c|}
\hline & \multicolumn{3}{|c|}{$\begin{array}{l}\text { Radiation Measured } \\
\text { in Quarterly Average }\end{array}$} & \multicolumn{3}{|c|}{$\begin{array}{c}\text { Radiation Measured } \\
\text { in Quarterly Maximum }\end{array}$} \\
\hline & (1) & $(2)$ & (3) & $(4)$ & $(5)$ & (6) \\
\hline \multirow[t]{2}{*}{$S$} & -0.2375 & -9.3376 & $0.2399^{* * *}$ & -0.2399 & $0.4128^{*}$ & $0.2366^{* * *}$ \\
\hline & $(0.2379)$ & $(278.1116)$ & $(0.0435)$ & $(0.2792)$ & $(0.1964)$ & $(0.0419)$ \\
\hline \multirow[t]{2}{*}{$S \times R_{1}$} & $0.1550^{*}$ & & & 0.1564 & & \\
\hline & $(0.0733)$ & & & $(0.0864)$ & & \\
\hline$S \times R_{2}$ & & $\begin{array}{c}6.7942 \\
(196.8760)\end{array}$ & & & $\begin{array}{l}-0.0808 \\
(0.0554)\end{array}$ & \\
\hline$S \times R_{3}$ & & & $\begin{array}{c}-0.0403^{* * *} \\
(0.0071)\end{array}$ & & & $\begin{array}{c}-0.0268^{* * *} \\
(0.0045)\end{array}$ \\
\hline$N$ & 255697 & 259371 & 261204 & 255697 & 259371 & 261204 \\
\hline $\begin{array}{l}\text { Cragg-Donald F- } \\
\text { Statistics }\end{array}$ & 1.598 & 1.598 & 19.411 & 1.598 & 1.597 & 20.669 \\
\hline $\begin{array}{l}\text { Kleibergen-Paap F- } \\
\text { Statistics }\end{array}$ & 1.685 & 1.685 & 18.312 & 1.685 & 1.086 & 20.502 \\
\hline
\end{tabular}

Standard errors in parentheses

$* p<0.05, * * p<0.01, * * * p<0.001$

This table reports the 2SLS estimates for the effect of education on the log wage income. The effect of education on wage is allowed to vary with infancy radiation exposure, and therefore the interaction of education and radiation is set as an additional endogenous variable in the first stage. Education $(\$ S \$)$ and the education-radiation interaction $(S \times R)$ are together instrumented by the local number of colleges. Infancy radiation exposure in the three postnatal quarters $R_{1}, R_{2}$, and $R_{3}$ are used as shifters of unobserved latent abilities. Alternative definitions of $\$ \mathrm{R}$ 's $\$$ as the average and the maximum radiation in each of the individual's postnatal quarters are considered separately. For Columns (1) and (4), radiation in the first postnatal quarter is considered; for Columns (2) and (5), radiation in the second postnatal quarter is considered; for Columns (3) and (6), radiation in the third postnatal quarter is considered. Age, age square, race, whether living in metropolitan areas, the state-level unemployment, a linear trend of the survey year, the birth state fixed effect, and the birth year fixed effect are included as controlled covariates. Standard errors are clustered by the birth state and the birth year.

Age, age square, race, whether living in metropolitan areas, the state-level unemployment, a linear trend of the survey year, the birth state fixed effect, and the birth year fixed effect are included as controlled covariates. Standard errors are clustered by the birth state and the birth year.

Figure 2 and Figure 3 provide visualization of the diminishing marginal return to education with the increase on infancy radiation in the third postnatal quarter. The 2SLS estimates for the effect of education on wage turn from positive to zero for individuals experiencing an approximate level of radiation of one standard deviation beyond the mean of the quarterly radiation in the third postnatal quarter. This pattern is persistent when the quarterly radiation in the third postnatal quarter is defined as the quarterly average or the quarterly maximum. 
FIGURE 2

2SLS ESTIMATES FOR EFFECTS OF EDUCATION ON LOG WAGE WITH RADIATION IN QUARTERLY AVERAGE

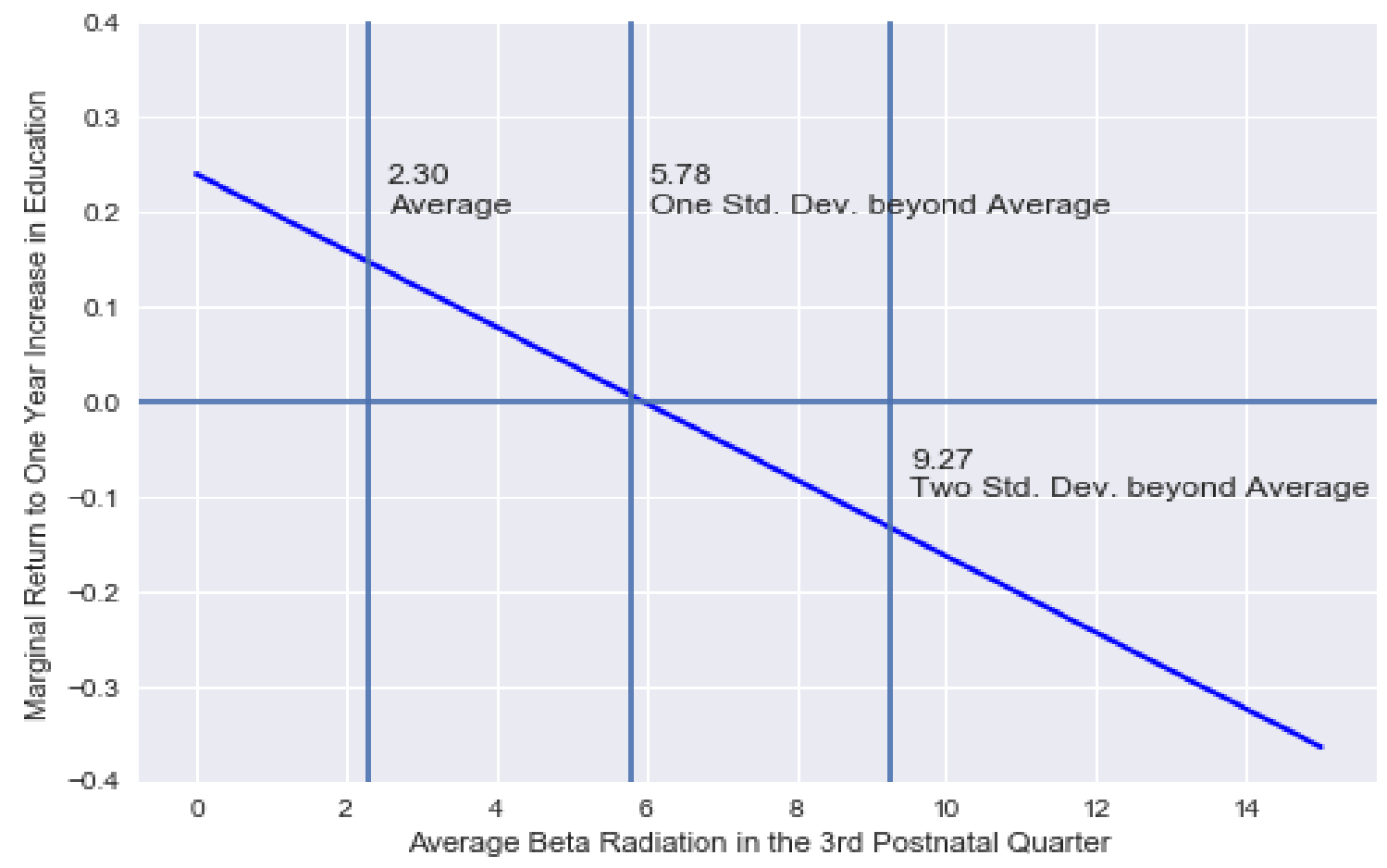

FIGURE 3

2SLS ESTIMATES FOR EFFECTS OF EDUCATION ON LOG WAGE WITH RADIATION IN QUARTERLY MAXIMUM

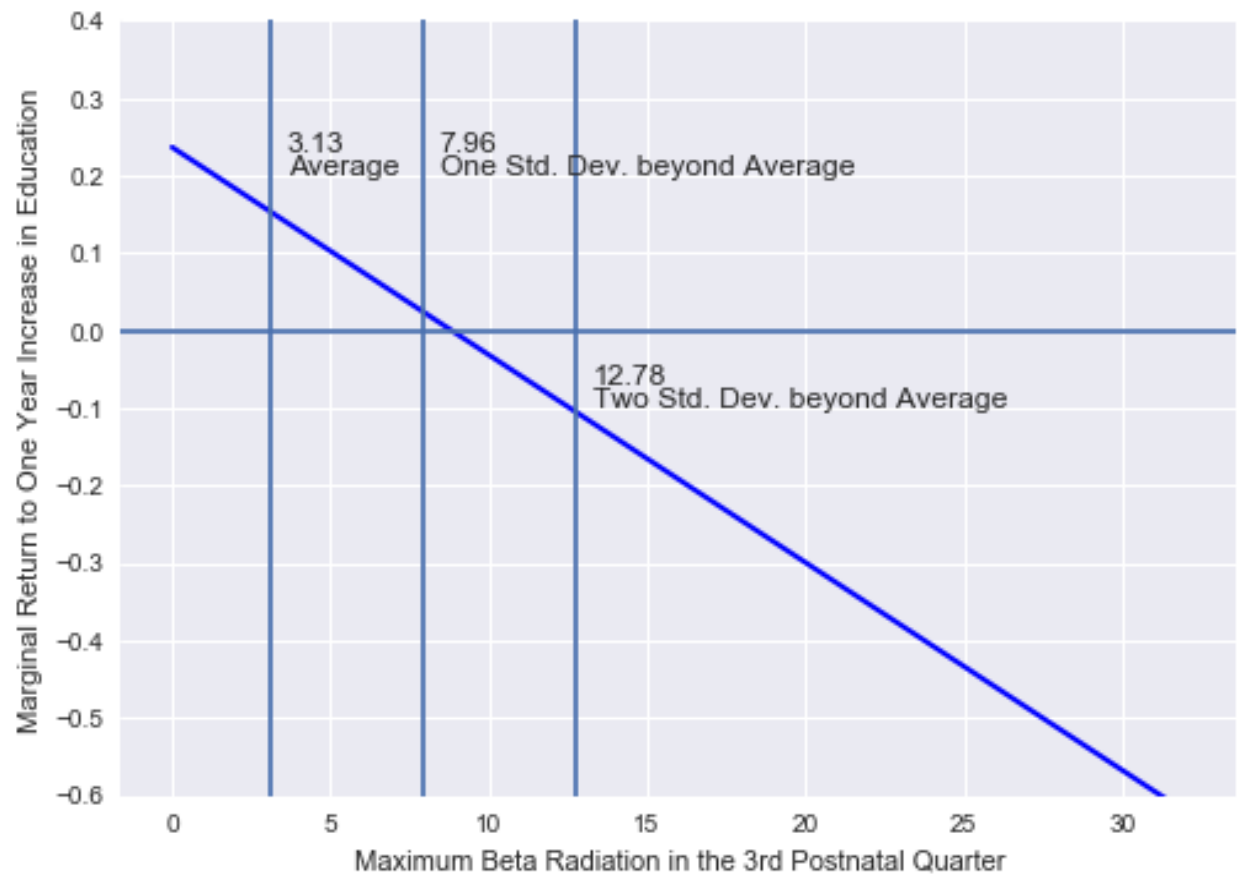




\section{CONCLUSIONS}

There are three main findings regarding estimating the effect of education on wage using school openings as the instrumental variable and infancy radiation exposure as a shifter to unobserved heterogeneity.

First, the standard IV estimation is robust to the inclusion of infancy radiation exposure. In the regression of education on local numbers of four/two-year colleges, the openings of four-year colleges have a positive effect on educational attainment, and the openings of two-year colleges have negative effects. The inclusion of radiation in the three postnatal quarters to the education equation contributes to very little additional explanatory power. Only radiation in the third postnatal quarter has statistical significance. The inclusion of infancy radiation exposure in the as additional control covariates in the IV first -stage regression does not alter the 2SLS IV estimates.

Second, the infancy radiation exposure affects the educational attainment through altering the effect of two-year college numbers. Considering a non-linear effect of infancy radiation exposure in the IV firststage regression, radiation interacts with the number of four/two-year colleges. It is shown that the effect of four-year college openings on educational attainment does not change with radiation in the three postnatal quarters. The effect of two-year college openings on education becomes less negative for individuals with stronger radiation in their third postnatal quarter. The finding suggests that the inclusion of radiation in the third postnatal quarter takes effects by making educational attainment less sensitive to two-year college openings, but does not alter the 2SLS IV estimates

Third, the effect of educational attainment on wage decreases with a stronger infancy radiation exposure. The number of endogenous regressors becomes two: educational and the education-radiation interaction. The instrumental variable set remains the number of four- and two-year colleges. When considering the interaction of education with radiation in the first or the second postnatal quarter, the IV model is weakly identified (low Cragg-Donald F-statistics). Both the number of four-year colleges and the number of two-year colleges have the significant positive effect on the interaction of educational attainment and radiation in the third postnatal quarter. The 2SLS estimates for the effect of education and radiationeducation interactions show that the return to education decreases with infancy radiation exposure, and can go from positive to negative for individuals with extreme radiation in their third postnatal quarters.

It is suggested that the 2SLS IV estimation is robust to modifications to the baseline model by allowing linear and non-linear effects of infancy radiation exposure in the first stage. There is no significant evidence that the college number IV violate the exclusion restriction assumption. Educational attainment is not sensitive to infancy radiation exposure given the control for local school openings. However, the effect of educational attainment on wage is sensitive to infancy radiation exposure in the third postnatal quarter. There are heterogeneous IV treatment effects on wage for people with different abilities.

\section{ENDNOTES}

1. Currie and Moretti (2003) propose four-year and two-year college openings as IVs for maternal education to estimate its effect on newborn birth outcomes.

2. 120 Years of American Education: A Statistical Portrait (1999).

3. Radiation in the first quarter is not used to construct infancy radiation exposure due to the selection of analyzed population sample (see detail in Section 3.3 and 3.4). The summary statistics of the average and the maximum radiation in the first quarters are thus not reported.

4. The detailed description of the school opening data is available in the appendix of Currie and Mariotte (2003).

5. In the 2005-2015 ACS data, the variable of usual hours worked per week is available. However, the detailed "weeks worked last year" is only available in the 2005-2007 interview. In the 2008-2015 ACS data, the information of weeks worked last year is only available in intervals. I use the mid-value of the reported interval to proxy the number of working hours for the 2008-2015 sample. For the 2005-2007 sample, detailed numbers of working hours are used to calculate the hourly wage rate.

6. In the Currie and Moretti (2003) paper, the number of colleges are identified to the county level. In this paper, I merged the number of colleges to the PUMA-level, since it is the smallest geographic identifier for all 
respondents in the ACS sample.

7. In the ACS data, the most precise information of the birth timing is the individual's quarter of birth. The postnatal radiation to an individual is thus defined as radiation levels in the consecutive quarters following the individual's birth quarter. Details in the data construction are provided in the data section.

8. The detail description of the sample selection is provided in the data section.

9. An alternative approach to test the additional explaining power of infancy radiation exposure to schooling is to calculate the partial R-square from the inclusion of infancy radiation exposure to the regression of education on local college numbers. The partial R-squares are reported in the Appendix Tables.

\section{REFERENCES}

Almond, D. (2006). Is the 1918 Influenza Pandemic Over? Long-Term Effects of Utero Influenza Exposure in the Post-1940 U.S. Population. Journal of Political Economy, 114(4), 672-712.

Almond, D., \& Currie, J. (2011). Killing Me Softly: The Fetal Origin Hypothesis. Journal of Economic Perspectives, 25(3), 153-172.

Almond, D., Edlund, L., \& Palme, M. (2009). Chernobyl's Subclinical Legacy: Prenatal Exposure to Radioactive Fallout and School Outcomes in Sweden. Quarterly Journal of Economics, 124, 1729-1772.

American Academy of Pediatrics. (1998). Risk of ionizing radiation exposure to children: A subject review. Pediatrics, 101, 717-719.

Auvinen, A., Vahteristo, M., Arvela, H., Suomela, M., Rahola, T., Hakama, M., \& Rytmaa1, T. (2001). Chernobyl Fallout and Outcome of Pregnancy in Finland. Environmental Health Perspectives, 109(2), 179-185.

Black, S.E., Butikofer, A., Devereux, P.J., \& Salvanes, K.G. (2013). This Is Only a Test? Long-Run Impacts of Prenatal Exposure to Radioactive Fallout. NBER Working Paper No.18987.

Black, S.E., Devereux, P.J., \& Salvanes, K.G. (2007). From the Cradle to the Labor Market? The Effect of Birth Weight on Adult Outcomes. Quarterly Journal of Economics, 122, 409-439.

Brenner, D.J., Doll, R., Goodhead, D.T., Hall, E.J., Land, C.E., Little, J.B., . . Zaider, M. (2013). Cancer Risks Attributable to Low Doses of Ionizing Radiation: Assessing What We Really Know. Proceedings of the National Academy of Sciences, 100(13), 761-766.

Card, D. (2001). Estimating the Return to Schooling: Progress on Some Persistent Economic Problems. Econometrica, 69(5), 1127-1160.

Carneiro, P., Heckman, J.J., \& Vytlacil, E.J. (2011). Estimating Marginal Returns to Education. American Economic Review, 101(6), 2754-2781.

Case, A., Lubotsky, D., \& Paxson, C. (2002). Economic Status and Health in Childhood: The Origins of the Gradient. American Economic Review, 92(5), 1308-1334.

Chang, T-J. (2017). Testing the Fetal Origin Hypothesis: The Case of U.S. Prenatal Radiation Exposure in the 1960s. Working Paper.

Currie, J., \& Moretti, E. (2003). Mother's Education and the Intergenerational Transition of Human Capital: Evidence from College Openings. Quarterly Journal of Economic, 518(4), 1495-1532.

Currie, J., \& Moretti, E. (2007). Biology as Destiny? Short and Long-Run Determinants of Intergenerational Transition of Birth Weight. Journal of Labor Economics, 25(2), 231-264.

De Santis, M., Di Gianantonio, E., Straface, G., Cavaliere, A.F., Caruso, A., Schiavon, F., . . Clementi, M. (2005). Ionizing Radiations in Pregnancy and Teratogenesis: A Review of Literature. Reproductive Toxicology, 20, 323-329.

Ericson, A., \& Källén, B. (1994). Pregnancy Outcome in Sweden After the Chernobyl Accident. Environmental Research, 67(2), 149-159.

Fukuda, M., Fukuda, K., Shimizu, T., \& Moller, H. (1998). Decline in Sex Ratio after Birth after Kobe Earthquake. Human Reproduction, 13, 2321-2322.

Hamilton, P.M., Roney, P.L., Keppel, K.G., \& Placek, P.J. (1984). Radiation Procedures Performed on U.S. Women During Pregnancy: Findings from Two 1980 Surveys. Public Health Reports, 99(2), 
146-151.

Hohenemser, C. (1988). The Accident at Chernobyl: Health and Environmental Consequences and the Implications for Risk Management. Annual Review of Energy, 13, 383-428.

Holmberg, M., Edvarson, K., \& Finck, R. (1988). Radiation Doses in Sweden Resulting from the Chernobyl Fallout: A Review. International Journal of Radiation Biology, 54(2), 151-166.

Imbens, G.W., \& Angrist, J.D. (1994). Identification and Estimation of Local Average Treatment Effects. Econometrica, 62(2), 467-475.

Kemkes, A. (2006). Secondary Sex Ratio Variation During Stressful Times: The Impact of the French Revolutionary Wars on a German Parish (1787-1802). American Journal of Human Biology, 18, 806-821.

Kolominsky, Y., Igumnov, S., \& Drozdovitch, V. (1999). The Psychological Development of Children from Belarus Exposed in the Prenatal period to Radiation from the Chernobyl Atomic Power Plant. Journal of Child Psychology and Psychiatry, 40(2), 299-305.

Laziuk, G.I., Zatsepin, I.O., Verger, P., Gagniere, V., Robert, E., Kravchuk, Z.P., \& Khmel, R.D. (2002). Down Syndrome and Ionizing Radiation: Causal Effect or Coincidence. Radiatsionnaia Biologiia, Radioecologiia, 42(6), 678-683.

Lee, S., Otakeand, M., \& Schull, W.J. (1999). Changes in the Pattern of Growth in Stature Related to Prenatal Exposure to Ionizing Radiation. International Radiation Biology, 75(11), 1449-1458.

Lin, M-J., Liu, J-T., \& Chou, S-Y. (2007). As Low Birth Weight Babies Grow, Can Well-Educated Parents Buffer This Adverse Factor? A Research Note. Demography, 44(2), 335-343.

Nowakowski, R.S., \& Hayes, N.L. (2008). Radiation, Retardation and the Developing Brain: Time is the Crucial Variable. Acta Pdiatrica, 97, 527-531.

Oreopoulos, P. (2006). Estimating Average and Local Average Treatment Effects of Education when Compulsory Schooling Laws Really Matter. American Economic Review, 96(1), 152-175.

Otake, M., \& Schull, W.J. (1984). In Utero Exposure to A-Bomb Radiation and Mental Retardation. A Reassessment. British Journal of Radiology, 57, 409-414.

Otake, M., \& Schull, W.J. (1998). Review: Radiation-related Brain Damage and Growth Retardation Among the Prenatally Exposed Atomic Bomb Survivors. International Journal of Radiation Biology, 74(2), 159-171.

Sandersona, E., \& Windmeijer, F. (2016). A Weak Instrument F-Test in Linear IV Models with Multiple Endogenous Variables. Journal of Econometrics, 190, 212-221.

Schull, W.J., \& Otake, M. (1999). Cognitive Function and Prenatal Exposure to Ionizing Radiation. Teratology, 59, 222-226.

St Clair, D., Xu, M., Wang, P., Yu, Y., Fang, Y., Zhang, F., .. He, L. (2005). Rates of Adult Schizophrenia Following Prenatal Exposure to the Chinese Famines of 1959-1961. Journal of the American Medical Association, 294(5), 557-562.

Stephens, M., Jr., \& Yang, D-Y. (2014). Compulsory Education and the Benefits of Schooling. American Economic Review, 104(6), 1777-1792.

Stock, J., \& Yogo, M. (2002). Testing for Weak Instruments in Linear IV Regression. NBER Technical Working Paper No. 284. 